\title{
Pro-inflammatory Cytokines (IL6, IL8 and TNF- $\alpha$ ) in the Evaluation of Ovarian Endometriosis Cyst
}

\author{
CAROLINA GOBJILA ${ }^{1 *}$, MARIUS LUCIAN CRAINA ${ }^{1 \#}$, DANIELA OANA TOADER ${ }^{2 \#, ~ I Z A B E L L A ~ P E T R E}{ }^{1}$, \\ CORNELIU BOGDAN ANDOR ${ }^{3 *}$, ANCA TUDOR ${ }^{4 *}$, ROXANA RAMONA ONOFREI ${ }^{5 *}$, LIVIU ATHOS TAMAS6*, \\ ADRIAN COSMIN ILIE' \\ 'University of Medicine and Pharmacy Victor Babes Timisoara, Department XII, Discipline of Obstetrics and Gynecology, \\ 2 Eftimie Murgu Sq., 300041,Timisoara, Romania \\ ${ }^{2}$ National Institute for Mother and Child Health, Alessandrescu - Rusescu Bucharest, Polizu Clinical Hospital, $38-52$ Gheorghe \\ Polizu Str., 022455, Bucharest, Romania \\ ${ }^{3}$ University of Medicine and Pharmacy Victor Babes Timisoara, Department XV of Orthopedics, Traumatology, Urology and \\ Medical Imaging, Timisoara, Romania \\ ${ }^{4}$ University of Medicine and Pharmacy Victor Babes Timisoara, Department of Functional Sciences, Medical Informatics and \\ Biostatistics Discipline, 2 Eftimie Murgu Sq., 300041,Timisoara, Romania \\ 5 University of Medicine and Pharmacy Victor Babes Timisoara, Department of Rehabilitation, Physical Medicine and Rheumatology, \\ 2 Eftimie Murgu Sq., 300041,Timisoara, Romania \\ EUniversity of Medicine and Pharmacy Victor Babes Timisoara, Department II, Discipline of Biochemistry and Pharmacology, \\ 2 Eftimie Murgu Sq., 300041, Timisoara, Romania \\ ZUniversity of Medicine and Pharmacy Victor Babes Timisoara, Department of Anatomy and Embryology, 2 Eftimie Murgu Sq., \\ 300041, Timisoara, Romania
}

\begin{abstract}
Endometriosis is the abnormal growth of cells (endometrial cells) similar to those that form the inside of the uterus, but in a location outside of the uterus. Endometriosis is most commonly found on other organs of the pelvis. These lesions are most commonly found on the ovaries, the Fallopian tubes, the surface of the uterus, the bowel, and on the membrane lining of the pelvic cavity (i.e. the peritoneum). We corroborate TNF- $\alpha$, IL-6 and IL-8 markers with intraoperative laparoscopic on 39 patients diagnosed with endometriosis in January 2016 - December 2017, aged 20-45 years. There has been a preoperative evaluation in the patients from this that included the anamnesis, clinical examination and laboratorytests. Anamnesis recorded demographic details, patient's personal, physiological and pathological medical history. Evaluation of preoperative investigations consisted of general and local systems examination, a gynecological examination in order to identify the specific signs of endometriosis. Making matters worse is that endometriosis exhibits significant immunological dysfunction, including the over-expression of pro-inflammatory cytokines like interleukin-1 (IL-1), interleukin-6(IL-6), and tumor necrosis factor (TNF), all of which contribute to a chronic up-regulation of painful, tissue-damaging inflammatory processes. Because the cause of endometriosis is poorly understood, there are no known ways to prevent its development.
\end{abstract}

Key words: ovarian endometriosis cyst, pro-inflammatory cytokines, IL6, IL8, TNF- $\alpha$

Endometriosis is defined as the presence of endometrial tissue outside of the uterus. Unfortunately, this pathology is more common in fertile people aged $16-50$ years, characterized by increasingly worsened pain and subfertility [1-2]. Women with endometriosis have symptoms that include chronic pelvic pain, dysmenorrhea and dyspareunia, that significantly reduce the quality of their life.

In the pathogenesis of endometriosis inflammation plays an important role. Infiltration of local proinflammatory mediators in the peritoneal environment affects ovarian function and anatomy of the pelvis. All these outlines, later, the picture of symptomatic endometriosis. Pathophysiological, there is an acute inflammation followed by macrophage infiltration, tissue remodelling and neovascularization [3].

The responses to the inflammatory process are directly correlated with the growth of activated macrophages and cytokines secreted into the peritoneal fluid, thereby producing maintenance of endometrioses by endometrial adhesion, invasion, angiogenesis and endometrial cell proliferation within endometrial deposits [4-6].
Although the pathogenesis of endometriosis is still controversial, a widely accepted explanation is that of Sampson's theory according to which the flow of menstrual blood determines the displacementand storage of endometrial cells at unusual locations (Sampson's theory of retrograde menstruation).

There are numerous studies that report that a series of biomarkers (IL-6, IL-8, TNF- $\alpha$, high sensitivity C-reactive protein and antigens CA125 and CA19-9) show with high sensitivity and correlated with clinical symptoms the clinical forms of endometriosis.

\section{Experimental part \\ Material and methods}

In our study group of 39 patients diagnosed with ovarian endometriosis cyst, the dosage of immunological markers and cytokine IL-6, IL-8 and TNF- $\alpha$ levels in serum was performed preoperatively and 6 months after surgery. We compared marker values for patients diagnosed with endometriosis with those of a control group ( 26 cases) to whom this diagnosis was not confirmed. The data was processed using SPSS v17 statistical package software. 
Table 1

VALUES OF CENTRAL AND DISPERSION TREND INDICATORS FOR THE IL- 6 VARIABLE

\begin{tabular}{|l|l|l|}
\hline Indicators & IL-6 Control & IL-6 Study \\
\hline Mean & 3.628 & 6.36 \\
\hline $95 \%$ Interval Confidence Lower Bound & 2.401 & 5.244 \\
\hline $95 \%$ Interval Confidence Upper Bound & 4.8556 & 7.476 \\
\hline Median & 2.195 & 6.01 \\
\hline Variance & 9.236 & 11.852 \\
\hline Std. Deviation & 3.039 & 3.443 \\
\hline Std. Error & 0.596 & 0.551 \\
\hline Minimum & 0.36 & 1.37 \\
\hline Maximum & 14.30 & 13.32 \\
\hline Range & 13.94 & 11.95 \\
\hline Skewness & 1.901 & 0.120 \\
\hline Kurtosis & 4.888 & -1.207 \\
\hline
\end{tabular}

Table 2

VALUES OF CENTRAL AND DISPERSION TREND INDICATORS FOR THE TNF VARIABLE

\begin{tabular}{|l|l|l|}
\hline Indicators & TNF Control & TNF Study \\
\hline Mean & 57.731 & 54.525 \\
\hline $95 \%$ Interval Confidence Lower Bound & 54.894 & 52.308 \\
\hline $95 \%$ Interval Confidence Upper Bound & 60.578 & 56.743 \\
\hline Median & 58.38 & 54.61 \\
\hline Variance & 49.331 & 46.782 \\
\hline Std. Deviation & 7.024 & 6.839 \\
\hline Std. Error & 1,377 & 1.095 \\
\hline Minimum & 40.03 & 37.24 \\
\hline Maximum & 67.92 & 68.06 \\
\hline Range & 27.89 & 30.82 \\
\hline Skewness & -0.520 & -0.197 \\
\hline Kurtosis & -0.141 & -0.302 \\
\hline
\end{tabular}




\begin{tabular}{|l|l|l|}
\hline Indicators & IL-8 Control & IL-8 Study \\
\hline Mean & 31.995 & 76.613 \\
\hline $95 \%$ Interval Confidence Lower Bound & 28.238 & 59.340 \\
\hline $95 \%$ Interval Confidence Upper Bound & 35.752 & 93.886 \\
\hline Median & 34.900 & 44.300 \\
\hline Variance & 215.214 & 2839.394 \\
\hline Std. Deviation & 14.670 & 53.286 \\
\hline Std. Error & 1.878 & 8.533 \\
\hline Minimum & 4.700 & 40.100 \\
\hline Maximum & 110.800 & 228.000 \\
\hline Range & 106.100 & 187.900 \\
\hline Skewness & 2.080 & 1.560 \\
\hline Kurtosis & 13.348 & 1.668 \\
\hline
\end{tabular}

Table 3

VALUES OF CENTRAL AND DISPERSION TREND INDICATORS FOR THE IL-8 VARIABLE

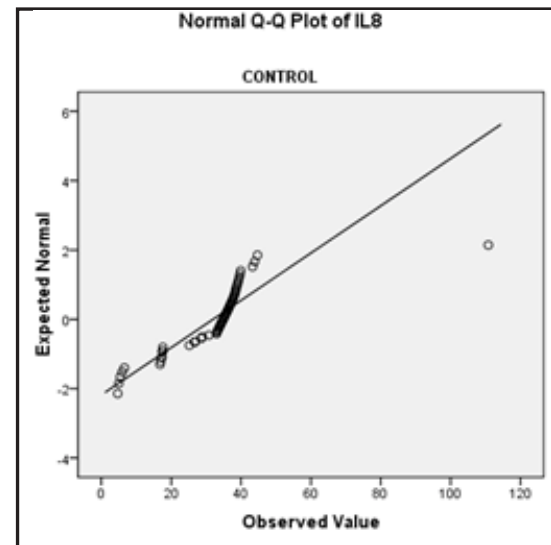

IL-8 values for patients in the control group do not follow a normal distribution (Shapiro-Wilk normality test, $p<0.001$ )

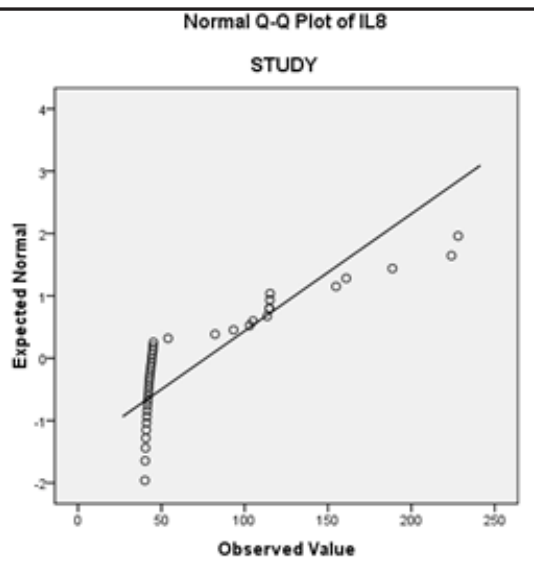

IL-8 values for the patients in the study group do not follow a normal distribution (Shapiro-Wilk normality test, $p<0.001$ )

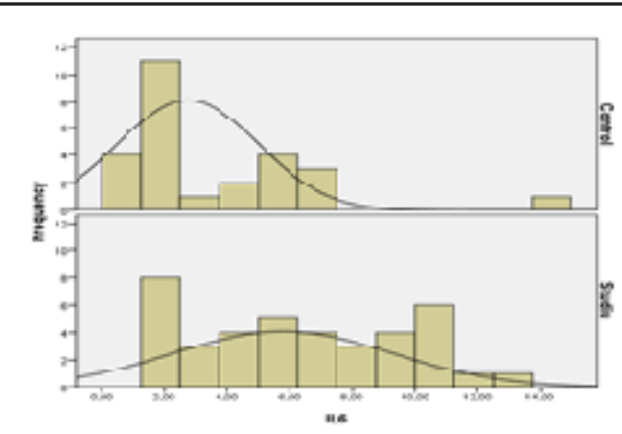

The histograms of IL- 6 values compared to the two samples

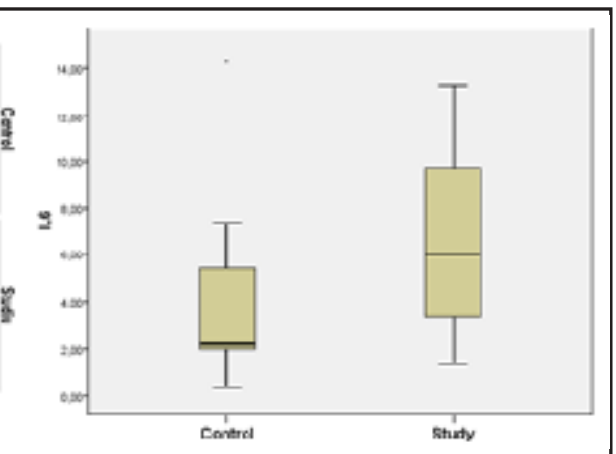

Box Plot representation of IL- 6 values compared to the two samples

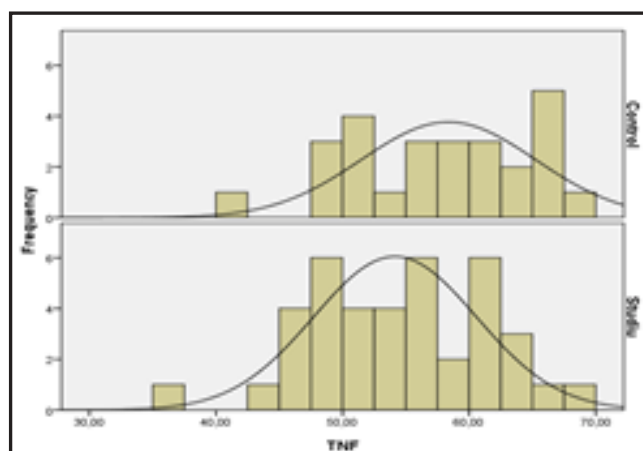

The Histograms of TNF values compared to the two samples

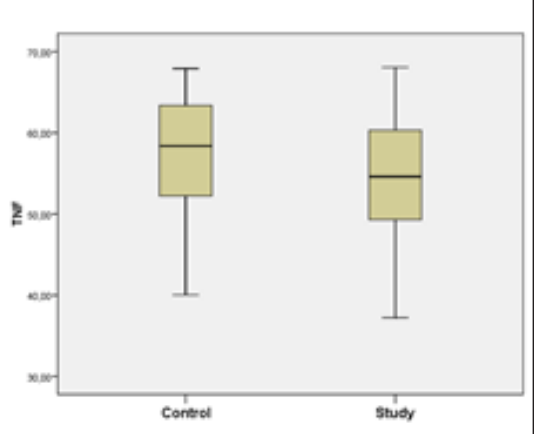

Box Plot representation of TNF values compared to the two samples
Fig. 3.The normal Q-Q plots for the IL - 8 values

Fig. 4. The histogram and the Box plot for the I - 6 , TNF and IL - 8 


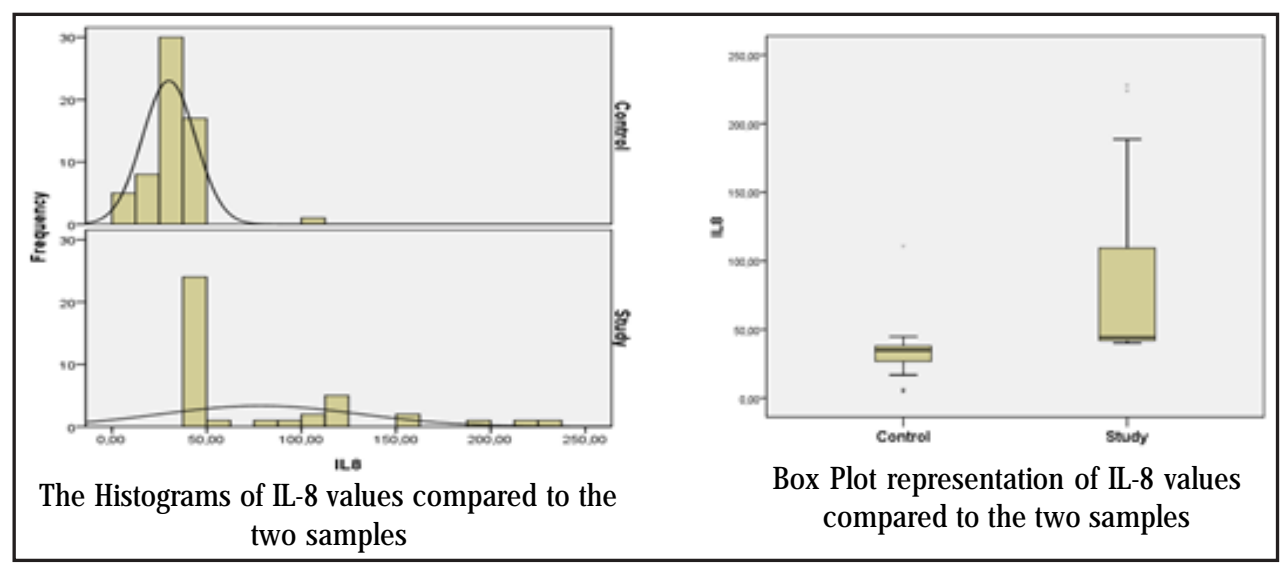

IL-6 values are significantly increased for the study group compared to control (Mann-Whitney U Test, $p=0.001$ ).

TNF values for the endometriosis group are insignificantly low (Unpaired t Test, $p=0.072$ ) (fig.5).

IL-8values are significantly increased for the study group compared to control (Mann-Whitney U Test, $p<0.001$ ) (fig. 6).

\section{Conclusions}

Pro-inflammatory cytokines appear to play an important role in the development of endometriosis, initially acting locally and then manifesting systemically, thus rendering the clinical picture of endometriosis. The high prevalence and severe consequences of this disease caused ta major public health issue in modern society. And yet, the mechanism responsible for the initiation and development of this disease still remains an enigma.

Identifying a non-invasive diagnostic marker for endometriosis could facilitate the early diagnosis of this pathology and early medical management with an appropriate treatment for each case.

\section{References}

1.YAGMUR E, BASTU E, KARAMUSTAFAOGLU-BALCI B, et al. Noninvasive diagnosis of endometriosis based on a combined analysis of four plasma biomarkers. Centr Eur J Immunol. 38:154-158, 2013.

2.MOINI A, MALEKZADEH F, AMIRCHAGHMAGHI E, et al. Risk factors associated with endometriosis among infertile Iranian women. Arch Med Sci., 9:506-514, 2013.

3.CUFF J, LONGACRE T.A. Endometriosis does not confer improved prognosis in ovarian carcinoma of uniform cell type. Am J Surg Pathol.May;36(5), 2012.

4.GOBJILA, C., ANASTASIU D., CRAINA M., CITU I., CITU C., PANTEA S., PETRE I., Correlations between Clinical and Imaging in Diagnosis of Endometriosis - Case Report, The 13th Conference of the Romanian-German Society of Obstetrics and Gynecology,Timi-oara, Romania, 14-16 September 2017, pag 151- 153, Ed. Filodiritto Editore Proceeding, 2017.
5.PETRE I., CRAINA M., BERNAD E., MOLERIU L.C., CITU I., CITU C., STELEA L., GOBJ ILA C., BOGLUT A., CRACIUN L., PANTEA S., Immunological Markers and Inflammatory Cytokines in Endometriosis, The 13th Conference of the Romanian-German Society of Obstetrics and Gynecology,Timi-oara, Romania, 14-16 September 2017, pg 243248, Ed. Filodiritto Editore Proceeding, 2017.

6.GOB] ILA C., PETRE I., CRAINA M., IONITA I., MOLERIU R.D., BOGLUT A., MILOICOV O.C. BACEAN, CRACIUN L., Corroboration of Ultrasound Aspects with the AL CA - 125 Seric Levels and with Intraoperative Laparoscopic Images in Cases of Pelvic Endometriosis, 5th Congress Of The Romanian Society Of Ultrasound In Obstetrics and Gynecology, Filodiritto Editore Proceeding, Targu Mures, Romania, pg 487- 491, 2017.

7.GOBJ ILA C., CRAINA M., PETRE I., IACOB R., POP E., BOLINTINEANU S.L., MOLERIU L.C., TIMAR B., TIMAR R., PANTEA S. - Clinical Features, Mr Imaging Findings and Pathologic Correlation in the Diagnosis of Endometriosis, The 4 th Congress of the Romanian Society for Minimal Invasive Surgery in Gynecology, Annual Days of the National Institute for Mother and Child Health Alessandrescu-Rusescu, 1-3 November, 2018, Bucharest, Romania, pag 277-283, Ed. Filodiritto Editore Proceedings, 2019.

8.GOBJ ILA C., CRAINA M., PETRE I., IACOB R., POP E., BOLINTINEANU S.L., STOIAN D., MOLERIU R.D., TIMAR B., TIMAR R., PANTEA S. - The Study of Biomarkers for the Ovarian Endometriotic Cyst Pathology, The 4 th Congress of the Romanian Society for Minimal Invasive Surgery in Gynecology, Annual Days of the National Institute for Mother and Child Health Alessandrescu-Rusescu, 1-3 November, 2018, Bucharest, Romania, pag 292-297, Ed. Filodiritto Editore Proceedings, ISBN 978-88-85813-48-9, 2019.

9.LIN SC, LI YH, WU MH, et al. Suppression of COUP-TFII by proinflammatory cytokines contributes to the pathogenesis of endometriosis. J Clin Endocrinol Metab. 2014;99:e427e437

10.NOMURA H, OKUDA K, SAITO N, et al. Mini-laparoscopic surgery versus conventional laparoscopic surgery for patients with endometriosis. Gynecol Minim Invasive Ther. 2013;2:85e88.

11.MIHALYI A, GEVAERT 0, KYAMA CM, et al. Non-invasive diagnosis of endometriosis based on a combined analysis of six plasma biomarkers. Hum Reprod ;25:654e664, 2010.

12.SEEBER B, SAMMEL MD, FAN X, et al. Panel of markers can accurately predict endometriosis in a subset of patients. Fertil Steril. 89:1073e1081, 2008.

$\overline{\text { Manuscript received:17.01.2019 }}$ 